\title{
Gobierno e inicio de la recaudación áurea en el Nuevo Mundo
}

István Szászdi

Universidad de Valladolid

La presente investigación trata de aclarar el insólito gobierno colombino de la isla Española. Queremos atender a algunas peculiaridades de aquel regimiento, así como rastrear los posibles precedentes institucionales. Se centra en el Consejo que el virrey de las Indias organizó en suelo antillano a raíz del segundo viaje, estudiando sus componentes y la dificultad de poder cumplir con su función de naturaleza gubernativa, sirviendo a los reyes sin contrariar al virrey que tenía aquella competencia por exclusiva de su persona.

A inicios de 1992 tuve la fortuna de hallar un viejo memorial dirigido a la reina Isabel de Castilla en el legajo 367 de Estado, en el Archivo General de Simancas. Por aquel entonces se encontraba becada por la Universidad de Valladolid la doctora Katalin Klimes-Szmik, quien impulsó la transcripción y estudio del memorial que bautizamos como Portugués. ${ }^{1}$

El objeto de la presente investigación es el estudio de las instituciones de gobierno durante el primer y segundo viaje colombino. No se puede continuar apreciando éstas de una manera aislada, cual si todo lo obrado por el almirante llevase un sello de singularidad. Es natural el creer que hubieran normas y precedentes para ellas, a pesar del mismo Cristóbal Colón. El feliz hallazgo del Libro Copiador nos sirve de pretexto para emprender esta delicada tarea.

\section{El regimiento de la Navidad}

En la carta-relación del segundo viaje, fechada en enero de 1494, el almirante narró la tragedia de los españoles a los reyes en los siguientes términos: "si se rrigieran según mi ynstruçión los constregía; que sobre todo

1 Dicho Memorial fue finalmente publicado tras dos años de espera, ofreciendo a los estudiosos de la Era de los Descubrimientos un manuscrito precioso lleno de noticias normalmente silenciadas por la política de sigilo portuguesa y la visión de personajes polémicos de la época. Szászdi León-Borja, István, y Katalin Klimes-Szmik: El Memorial Portugués de 1494. Una alternativa al Tratado de Tordesillas. Madrid, 1994. Sobre el Memorial véase también de Szászdi, István: "Las paces de Tordesillas en peligro. Los refugiados portugueses y el dilema de la guerra”, en Ana M. ${ }^{a}$ Carabias (edit.): Las relaciones entre Portugal y Castilla en la época de los descubrimientos y la expansión colonial, Salamanca, 1994, págs. 117-118. 
dexasen las mugeres ajenas y todas las de los yndios y nunca saliesen de la fortaleza a otra parte, salvo seis dellos y otros tantos después destos bueltos... y según eran todos ellos de poca criança, tirados dos u tres criados míos y este Pedro, rrepostero, se darían al comer y plazer de las mugeres; y ansí se perdieron y destruyeron así, y a mí an dado y dan tanta pena....'. Escobedo y el repostero encontraron la muerte, por cumplir con la "ynstruçión" del almirante.

Precisamente aquélla les unió hasta perecer en servicio. Rodrigo Escobedo — hombre de la más absoluta confianza del almirante - era el escribano de la Armada, natural de Segovia y sobrino de fray Juan Pérez, el gran valedor de Colón; mientras Pedro Gutiérrez era repostero de estrados del Rey y criado del despensero mayor. El Diario de Colón recoge el miércoles 2 de enero que: "Dejó en aquella isla Española... treinta y nueve hombres con la fortaleza... e sobre aquellos, por sus tenientes, a Diego de Arana... y a Pedro Gutiérrez... e a Rodrigo de Escovedo... con todos sus poderes que de los Reyes tenía". ${ }^{3}$ La carta del segundo viaje de enero de 1494, dice: "Este Arana, aunque fuese mui sobervio, tenía alguna criança, y le dexava el cargo del rregimiento al tiempo de mi partida; de que toda la gente quedava quexosa, y ansí le di en compañía a los otros dos, Pedro y Escobedo, y que se cumpliese lo que los dos acordasen". ${ }^{4}$

Diego de Arana, el capitán y alguacil, se vio marginado pronto del regimiento efectivo por Escobedo y Gutiérrez. Estos asumieron el gobierno y la justicia en la Navidad, destacándose Rodrigo Escobedo como el personaje decisorio de los dos. Así la muerte del genovés Jácome fue una auténtica ejecución legal y no el primer crimen en el Nuevo Mundo, como algunos han creído ver.

La conducta de los dos debe considerarse motivada por las propias instrucciones que dejó Cristóbal Colón, quien culparía a los castellanos del desastre, aún confesando — - según su suposición- que los dos tenientes habían obrado con probidad. En la misma carta, el almirante hacía relación según lo que supo por los indios: "y deçían quel comienço desta discordia fue que, luego que yo partí, cada uno no quiso estar a obediençia ni apañar oro salvo para sí, sino Pedro, rrepostero, y Escobedo; a éste avía yo dexa-

2 Manuscrito del Libro Copiador de Cristóbal Colón. Transcripción de Antonio Rumeu de Armas. Madrid, 1989. Tomo II, pág. 456.

3 Colón, Cristóbal: Los cuatro viajes del Almirante y su testamento. Edición y prólogo de Ignacio B. Anzoátegui. Madrid, 1982, pág. 117. Recoge la versión abreviada o sumario que del Diario hizo el padre Casas.

4 Libro Copiador, págs. 457-458. 
do el cargo de todas las cosas...". 5 Y esto último tiene importancia pues así se explica la visita que hizo Escobedo a Colón antes de partir, posteriormente a cuando Colón entregara su "ynstruçión", que deja ver un primer enfrentamiento de actitudes entre Rodrigo Escobedo y Arana: "vino a mí Escobedo, haziéndome saver como bien estava seguro, según el yndiçio quél avía avido, quél me ternía un tonel de oro aparejado quando yo bolviese, y esto fue a tiempo que yo ya anadava a la caravela; y me dixo que este Diego de Arana le avía dicho sobresta plática: Hagámonos el papo y después se procurará para el Rey. A que yo le rrespondí que tal cosa no hiziese, que rrico estava él harto, si servía a Vuestras Altezas, con tanta honrra y con este propósito se tornó a tierra". ${ }^{6}$ Lo que presumía una desautorización plena del deudo de su hijo Hernando.

Escobedo tenía muy presente cuál era la verdadera misión que Colón le había encomendado en su ausencia, el capítulo séptimo de su "ynstruçión” decía: "dejóles encomendado que cuando viesen que convenía, rogasen al rey que enviase con ellos algunos indios por la mar en sus canoas y algunos dellos se fuesen en la barca, como que querían ir a ver la tierra, por la costa o ribera de la mar arriba, y mirasen si descubriesen las minas del oro, pues les parecía que lo que les traían venía de hacia el Leste, que era aquel camino arriba, y allí les señalaban los indios nascer el oro... Item, que todo el oro que pudiesen buena y discretamente resgartar, lo resgatasen, porque cuando volviesen, hallasen cogido y allegado mucho"? Cosa que intentó cumplir, contando con el cacique guatiao como se le había instruído, quien narró a Colón que: "cada uno apartava oro para sí, salvo Pedro y Escobedo... y vinieron a bandos de que se pasó y que se apartaron... en tres partes; y que después dél, por su persona, aver ydo a la mina y llevado allá a Pedro y Escobedo, amostrando cómo se coxía el oro, quellos se determinaron para yr a otro rrey, a quien llaman Caonaboa... y quél les rrogó que no se fuesen que les daría pan y pescado y mugeres, y que nunca pudo acavar con ellos, salvo que tomaron sus mugeres y un fijico que tenía Pedro, y se fueron." Y añade el almirante "creo y digo otra vez que ovo defensión entre estos dos y Diego de Arana...”."

5 Ibídem, pág. 455. Inmediatamente después de la cita se cuenta cómo Gutiérrez y Escobedo fueron responsables de la muerte de Jácome, por lo que hay que creer que su ejecución se debió al apaño ilegal de oro, tratando así las autoridades de poner fin al mal ejemplo.

6 Ibídem, pág. 458.

7 Casas, Bartolomé de las: Historia de las Indias. Vol.I. Texto fijado por Juan Pérez de Tudela y Emilio López Oto. Madrid, 1957. Libro I, cap. LXIII, pág. 204.

8 Libro Copiador, pág. 457. El almirante llegó a sospechar que la quema de la Navidad misma fuera una venganza de Escobedo y de Gutiérrez contra Arana, poco conocía por entonces a Caonaboa. 
Colón, después de muertos, esperaba encontrar el oro que Escobedo y el repostero debían haber dejado a buen recaudo antes de su partida tierra adentro: "mandé cavar toda la casa fuerte, porque. en mi ynstruçión, les avía mandado que luego que algún oro tubiesen que lo pusiesen debajo de tierra, y no se halló cosa alguna". ${ }^{9}$ Sin lugar a duda, Escobedo y Gutiérrez nunca debieron explorar solos el interior, desoyendo a Guacanagarí, el cacique que les había ofrecido un eje de apoyo en la isla. Confiados en la mansedumbre de los indios, no temían daño alguno. Después de haber visto la mina del rey amigo, no quedaron satisfechos, y deseosos de descubrir el secreto de la tierra fueron en pos de las minas de Caonaboa, el señor de la Maguana, a pesar de los ruegos del guatiao quien temía lo peor. ${ }^{10}$ Pero su desobediencia se debió por conocer la realidad geográfica que confundía Colón, quien creía que Guarionex, Macorix y el Cibao eran islas "a Leste". Por eso el contenido del capítulo séptimo de su "ynstruçión". Cibao era Cipango, según Colón. Las Casas dice sobre esto que "los lugares que le nombraban no eran islas, sino provincias desta isla y tierras de señores, y esto significaban por los nombres: Guarionex era el rey grande de aquella vega real... querían decirle los indios... que en la tierra y reino de Guarionex estaba la provincia de Cibao, abundantísima de oro. Macorix era otra provincia...". ${ }^{11}$

La "conversación" entre Escobedo y Guacanagarí —el cacique guatiao de Colón - permitió al escribano y al repostero reunir los conocimientos básicos para la visita de las tierras mineras del interior, al cerciorarse del dislate geográfico del almirante. Colón en la carta-relación de enero, dice: "Quíseme yo yr para la nao y él [Guacanagarí] no quiso sino aconpañar, y le amostré los cavallos, de que ya tenía por oyda notiçia; y dixo que, al tiempo que Pedro Scobedo yba con él a la mina, que ellos casavan mucho y le deçían cómo en Castilla cabalgavan...". ${ }^{2}$ La tierra de las minas fue la atracción fatal de los castellanos.

Rodrigo Escobedo, por ser escribano de la Armada y hombre de confianza de Colón, fue uno de los primeros españoles que trató con Guacanagarí. El 23 de diciembre de 1492 había sido enviado por el almirante

9 Ibídem, pág. 456.

10 Szászdi, István: "Guatiao, los primeros tratados de Indias". Actas del IX Congreso del Instituto Internacional de Historia del Derecho Indiano. Madrid, 1991, tomo I, págs. 420-421.

11 Manzano, Juan: Colón y su secreto. El predescubrimiento. Madrid, 1982, págs. 373-375. En realidad Caonaboa, el cacique de la Maguana, era señor del Cibao - la tierra de las minas que en castellano significa "pedregal". Guarionex era el cacique de Maguá, la tierra ubicada entre la costa de los ciguayos y la sierra del Cibao, conocida como la Vega Real.

12 Libro Copiador, pág. 458. He corregido la transcripción de Rumeu parcialmente. 
al poblado del cacique indio, donde pasó el día agasajado. En ese día recibió el almirante noticias de la riqueza aurífera de la isla, dejando escrito en el Diario: "Nuestro Señor me adereçe, por su piedad, que halle este oro, digo su mina, que hartos tengo aquí que dizen que la saben". Al día siguiente los indios "nombravan donde se cogía el oro, dixeron de Cipango al cual ellos llaman Cibao, y allí afirman que hay gran cantidad... y quel cacique trae las vanderas de oro de martillo, salvo que está muy lexos, al Leste". ${ }^{13}$

El veedor Rodrigo Sánchez de Segovia regresó a Castilla, y Escobedo quedó como el hombre indiscutible al mando del regimiento de la Navidad. ${ }^{14}$ El repostero se había mostrado dócil con Colón — vio la luz que el almirante dijo ver la noche antes del descubrimiento- y era servidor de la Casa del rey. Pero no calibraríamos suficientemente la calidad del escribano Escobedo, que ya de por sí tenía un relieve enorme por su oficio, como vimos cuando tomó testimonio y dio fe el 12 de octubre de 1492 de la toma de posesión que hizo Colón en nombre de los reyes de la isla de Guanahaní, si no explicásemos que era contino de los reyes —oficio que le hacía estar en comunicación directa con sus altezas - gozando de su confianza plena y caracterizándose por su disponibilidad para asumir todo tipo de negocios. ${ }^{15}$

Si bien los continos carecen de un estudio institucional hasta ahora, resulta evidente su importancia dentro del gobierno de los Reyes Catolicos, y no es casualidad el gran número de continos utilizados por sus altezas para servir como corregidores. Y era el corregimiento la piedra esquinera de la reforma del gobierno local que hicieron Fernando e Isabel en Castilla.

Por todas estas razones Escobedo - y no Arana - se veía desde el comienzo llamado a asumir el papel de lugarteniente en ausencia de Cristóbal Colón. Lo que también explica que Gutiérrez, repostero de Estrados del rey, actuase al unísono con el contino de la reina. Sólo así se entiende la pasividad de Arana en un momento en que estaba en juego su

13 Manzano, Colón y su..., págs. 370-371. Banderas como insignias de los caciques fueron descubiertas por los españoles tanto en Jamaica como en Nicaragua, pero concretamente la bandera de oro de martillo de la cita debe relacionarse con las banderas de la costa ecuatoriana y del valle del Cauca. Según la descripción de Cieza de León eran piezas de oro martillado cosidas a la bandera. Szászdi, Adam: Un mundo que descubrió Colón. Las rutas del comercio de los metales. Cuadernos Colombinos XII, Valladolid, 1984, págs. 43, 128-129.

14 La relación entre Colón y el veedor nunca fue buena si se toma en cuenta que el almirante lo hizo apartar de la armada de 1493 en que iba de oficial de los contadores mayores. Gould, Alicia B.: Nueva lista documentada de los tripulantes de Colón en 1492. Madrid, 1984, págs. 434-435.

15 Ibídem, págs. 422-423. Según Alicia Gould, la reina nombró a Rodrigo de Escobedo su contino el 2 de febrero de 1486 con un sueldo de 20.000 maravedíes anuales. La Srta. Inés Rodríguez López se encuentra culminando una importante investigación sobre los continos en los reinos peninsulares que nos permitirá conocer su oficio y evolución. 
autoridad. Siendo capitán de la Navidad compartía el regimiento con otros dos, caso que, según mi conocimiento, era bien ajeno al modelo existente en el Castillo de San Jorge de la Mina. Lo que ofrece justificación a la organización gubernamental de la Navidad es la Capitulación de Santa Fe misma, dada en Santa Fe a 17 de abril y confirmada en Granada a 30 de abril de 1492: "Otrosi, que Vuestras Altezas fazen al dicho don Christoual su visorrey e gouernador general en todas las dichas yslas e tierras firmes e yslas, que, como dicho es, el descubriere o ganare en las dichas mares, e que para el rregimiento de cada vna e qualquier dellas faga eleçion de tres personas para cada ofiçio, e que Vuestras Altezas tomen e escojan vno, el que mas fuere su serviçio, e asi seran mejor regidas las tierras, que Nuestro Señor le dexara fallar e ganar a seruiçio de Vuestras Altezas. Plaze a Sus Altezas. Johan de Coloma". ${ }^{16}$ La terna de la Navidad se puede justificar así, pero el gusto del almirante por tener varios lugartenientes se haría evidente de nuevo.

\section{El Consejo del virrey de las Indias}

En el segundo viaje Colón hizo uso de un gobierno bicéfalo, en la carta-relación que escribió en torno al 20 de abril de 1494 a los reyes se lo comunicaba: "Para el gobierno de aquí e fecho y hordenado un consejo que las personas dél son éstas: Don Diego, mi hermano, fray Buil, presidentes, Pero Fernández Coronel, alguaçil maior, y a Alonso de Carvajal, rregidor de Baeza, Juan de Luxán, criado de Vuestras Altezas, y el bachiller Gallego". ${ }^{17}$ Luján y Carvajal eran continos de los reyes, por eso Colón llamó al primero "criado", ambos eran nobles al servicio de sus altezas que debían garantizar el buen orden del regimiento indiano. ${ }^{18}$

16 Rumeu de Armas, Antonio: Nueva luz sobre las capitulaciones de Santa Fe de 1492. Madrid, 1985, pág. 53. Libro de los privilegios del Almirante don Cristóbal Colón (1498). Estudio preliminar, edición y notas de Ciriaco Pérez-Bustamante. Madrid, 1951, págs. 32-33.

17 Libro Copiador, pág. 478. Valga añadir que el que Colón hubiera nombrado como miembros de su Consejo a dos hombres con experiencia en el gobierno como Carvajal y Luján muestra que el virrey deseaba establecer un híbrido entre un regimiento municipal castellano y un Consejo a imitación del Consejo Real.

18 Comunicación personal de la Srta. Inés Rodríguez López, fruto de sus investigaciones en el castillo de Simancas. Juan de Luxán, vecino de Madrid, aparece asentado en los pagos de quitaciones a los continos desde 1483. Luján fue maestresala de la princesa doña Isabel, Reina de Portugal, y en 1499 su hijo Miguel Ximenes de Luxan recibió la merced real de ser nombrado contino. En la documentación de los continos de los Reyes Católicos figuran tres Alonso de Carvajal, que quizás se pueden reducir a dos: uno hijo de Juan de Carvajal, otro hijo de Diego Sahez de Carvajal y un Comendador frey Alonso de Carvajal. 
Este Consejo del virrey con dos presidentes, debía garantizar el fácil control por parte del almirante de sus decisiones, consiguiendo en su ausencia - por causa de su exploración de las costas de Cuba- que no pudiera levantarse una personalidad contraria a sus deseos. ${ }^{19}$ La dicha carta de Colón a sus altezas de finales de abril, que conocemos desde el descubrimiento del Libro Copiador del almirante, quita cualquier género de duda de la naturaleza de la doble presidencia del Consejo. ${ }^{20}$

Que fray Bernardo Buyl actuó activamente como presidente, resulta evidente por la correspondencia oficial intercambiada entre los reyes y el virrey de las Indias, al igual que por los sucesos que llevaron al regreso de Buyl y de Margarit a España. La elección de Buyl para tal oficio se debió a la propia iniciativa de los reyes. No queda constancia directa, pero sí claros indicios, así en la carta de los reyes al almirante de 13 de abril de 1494, escrita en Medina del Campo, se decía al "Visorrey y Gobernador de las islas nuevamente falladas en las partes de las Indias" respecto de Bernal de Pisa —lugarteniente de los Contadores Mayores: "Nos habemos habido enojo de las cosas que allá se han fecho fuera de vuestra voluntad, las cuales mandaremos bien remediar e castigar. En el primer viaje que para acá se ficiere enviad a Bernal de Pisa, el cual Nos enviamos mandar que ponga en obra su venida, e en el cargo que llevó entienda en ello la persona que a vos e al padre fray Buil pareciere en tanto que de acá se provee, que por la priesa de la partida de los dichos navíos non se pudo agora proveer en ello, pero en el Primer Viaje, si place a Dios, se proveerá de tal persona cual conviniese para el dicho cargo". ${ }^{21}$ Se entiende, por lo anterior, que en caso de ausencia del virrey, éste escogiera a su hermano para reemplazarle pero siempre acompañado de fray Bernal para la toma de decisiones. Como vemos, Buyl no sólo era responsable del gobierno espiritual como legado del papa, sino que presidía en los negocios temporales de la Española. Los reyes tenían en él un fiel y valioso vasallo que muchas veces les había servido eficientemente en misiones de alta diplomacia..$^{22}$ Por ello el regreso de

19 Habrá que estudiar cómo se organizaba el gobierno de las colonias genovesas mediterráneas para asegurarnos de la originalidad del Consejo colombino.

20 García Gallo creía que Diego Colón era el lugarteniente único del virrey, conclusión natural producida por la lectura de Historia... de Las Casas y porque todavía no se había descubierto el Libro Copiador. García Gallo, Alfonso: Estudios de Historia del Derecho Indiano. Madrid. 1972, págs. 624-625.

21 Fernández de Navarrete, Martín: Colección de los viajes y descubrimientos que hicieron por mar los españoles desde fines del siglo XV. BAE. 75, Madrid, 1954, pág. 368.

22 Szászdi, István: “Guatiao, los...”, págs. 412-417, nota 16. 
Buyl a Europa por las discrepancias que mantenía el Consejo con el obrar de los Colón; además de su profunda desilusión ante los obstáculos para la conversión de los taínos y el fracaso de hallar el Cipango; constituyó un golpe durísimo para el virrey de las Indias. Esto queda evidenciado por el buen trato que recibió Buyl de los reyes, su interés por su opinión de lo sucedido en las Indias y en que sus altezas le proveyeron con una nueva y delicada misión en Roma. ${ }^{23}$

¿Se puede dudar de la capacidad de Buyl como presidente del Consejo del virrey de las Indias siendo éste en buena medida el responsable de la recuperación del Rosellón? Si recordamos los problemas del almirante con Margarit y con las lanzas jinetas, tenemos que concluir que el carácter de Colón hacía muy difícil que el Consejo pudiera asumir responsabilidades y tomar decisiones de gobierno. Tampoco era mossen Pedro Margarit ningún cualquiera; el hombre que regresó de las Indias con Buyl, en septiembre de 1494, había sido el capitán militar del virrey en el Cibao. Era contino del rey ${ }^{24}$ El regreso de las lanzas significaba el fracaso de la organización militar castellana en la isla Española. Verdaderamente el segundo viaje podría llamarse el viaje de los continos, pues ellos brillaron por su número y calidad. No sólo los ya señalados lo eran; por ser más conocido no hemos tratado de Antonio de Torres, contino, hermano del ama del príncipe, quien además de haber sido nombrado capitán de la nao "Marigalante" — y responsable de la correspondencia con los reyes como procurador de Colón ante ellos- fue designado por el virrey "Alcaide de la cibdat Isabela", cuyo protagonismo en el segundo viaje es notorio. ${ }^{25}$

Fernández de Oviedo, que habló con los regresados a España, dice: "e mandaron llamar el Rey y la Reina a fray Buyl e a mosén Pedro Margarite,

23 Szászdi, István: "Después de la Inter Caetera, ruptura y cambio en la política indiana de Alejandro VI." Memoria del X Congreso del Instituto Internacional de Historia del Derecho Indiano. México, 1995, T. II, págs. 1593, 1601-1605, 1613-1617.

24 Serrano y Sanz, Manuel: Orígenes de la dominación española en América. Madrid, 1918, págs. 235, 242, 253. Ramos Pérez, Demetrio: El conflicto de las lanzas jinetas. El primer alzamiento en tierra americana, durante el segundo viaje colombino. Valladolid, 1982, págs. 16, 134-136. Todo parece indicar que Mosén Pedro Margarit era un contino de guardas, tipo de continos que desempeñaban las armas y que estudia presentemente Inés Rodríguez López. Así se explica no sólo su participación en la guerra de Granada, sino el mando sobre los escuderos de las Guardas en la Española. Sobre su influencia en la corte ver Anglería, Pedro Mártir de: Décadas del Nuevo Mundo. Madrid, 1989. D. I, pág. 32. Añadir, finalmente, que el nombramiento del Consejo se debió hacer en la Isabela entre el 30 de marzo, que cayó domingo de Pascua, y el 20 de abril de 1492.

25 "Memorial que para los reyes dio el Almirante... en la ciudad de Isabela, a 30 de Enero de 1494 a Antonio de Torres, sobre el suceso de su segundo viaje a las Indias", en Colón, Cristóbal: Textos y documentos completos. Edición de Consuelo Varela y Juan Gil. Madrid, 1992, pág. 254. 
e fueron a España... e asimesmo el comendador Gallego, y el comendador Arroyo, y el contador Bernal de Pisa, e Rodrigo Abarca, e a Micer Girao, a Pedro Navarro, que todos éstos eran criados de la casa real; y llegados todos en España, cada uno se fue por su parte a la corte a besar las manos a los Católicos Reyes. E aunque por cartas desde acá, y después personalmente allá, oyeron a fray Buyl y otros quejosos, e fueron aquellos bienaventurados príncipes informados de las cosas del Almirante (e por ventura haciéndolas más criminales de lo que eran)... no solamente le perdonaron, pero diéronle licencia que tornase a la gobernación destas tierras...".

No interesan los errores en que pueda incurrir Oviedo respecto del retorno de los descontentos, sino su testimonio personal de haberles visto y hablado con ellos en la corte: "volvió Colom a España el año de mill e cuatroçientos e noventa e seis; así es la verdad; después de lo cual vi e hablé a algunos de los que con él tornaron a Castilla, así como el comendador mosén Pedro Margarite, e a los comendadores Arroyo e Gallego, e a Gabriel de León, e a Juan de la Vega, e a Pedro Navarro, repostero de camas del príncipe don Juan, mi señor, e a los más de los que se nombraron donde se dijo de algunos criados de la Casa Real que vinieron en el segundo viaje e descubrimiento destas partes. A los cuales y a otros oí muchas cosas de las desta isla, e de lo que vieron e padesçieron y entendieron del segundo viaje... he habido noticia de muchas cosas desta isla, de dos hidalgos que vinieron en el segundo viaje del Almirante, que hoy día estan aquí y viven en esta cibdad, que son Juan de Rojas e Alonso de Valencia, y de otros muchos testigos de vista... Y más que ninguno de todos los que he dicho, el comendador mosén Pedro Margarite, hombre principal de la Casa Real, y el Rey Católico lo tenía en buena estimación. Y este caballero fue el que el Rey e la Reina tomaron por principal testigo, e a quien dieron más crédito en las cosas que acá habían pasado en el segundo viaje...". Pero quedan otros pasajeros de ese viaje, que en el futuro deberán ser investigados, que son llamados criados de los reyes y que existe una gran probabilidad que también fueran continos. ${ }^{26}$

26 Fernández de Oviedo, Gonzalo: Historia general y natural de las Indias. Edición y estudio preliminar de Juan Pérez de Tudela Bueso. Madrid, 1992. Libro II, capítulos XIII y XIV. T. I, págs. 52-54. Es significativo que el único contino real que se ha dicho que apoyara a Colón de forma comprometida, de los que viajaron a las Indias en 1493, fuese Alonso Sánchez de Carvajal. La importancia de los continos en la Corte era enorme, los reyes los enviaban fuera del reino a negociar tratados, a sus ciudades para regir o corregir, para realizar pesquisas, al mando de lanzas para la guerra y un sinfín de otros servicios y oficios. Sobre esta importancia de los continos en la corte ver Fernández de Oviedo: Historia General... (capítulo IX). La participación de los continos reales debía causar desconfianza 
Carecemos de noticias sobre la división de responsabilidades entre los miembros del consejo colombino. Sólo tenemos un testimonio referente al contino Alonso Sánchez de Carvajal. En una instrucción de los reyes para Juan de Aguado, éstos le ordenaban: "Lo prymero, que los que hacá vyenen todos en xeneralmente se han quexado que, hansy hellos como los que alla quedan, syenpre han sydo maltratados delas personas que han tenydo los vastymentos en la repartyçion dellos, e espeçialmente teniendo el cargo dellos Caravajal que hacá vino, y Juan doñate despues del, porque dizen y afyrman todos que haçiendo el Juan doñate y los otros moços que halli tenia Caravajal mal recabdo en los vastymentos, dexaban moryr de hanbre a algunos honbres, entre los quales nonbran a un Loazes, gallego, y a otros, en tanto quel señor almyrante fue a descobryr, e por esto sus altezas mandan que se fyciese aca esta instruçion de lo que halla se les habia de dar, consultada con algunos de los que dalla vynieron." La experiencia de Carvajal en el regimiento de Baeza debió tener mucho que ver en que se le haya responsabilizado con la repartición de alimentos, pues eran los concejos quienes tenían que tomar medidas para evitar las sacas de trigo y el almacenamiento de los cereales en época de hambruna.

Esta instrucción fue mostrada a Cristóbal Colón por Aguado "el año de 95 en el mes de noviembre en las Indias", según anotó el virrey. En ella los reyes volvían a insistir en la necesidad de que se encomendara a sus criados o continos la administración de los mantenimientos entre los españoles de la isla de Haití: "lo prinçipal es quel señor almirante a de mandar remediar es que tenga vna persona o dos prinçipales, y que sean muy buenas personas, cryados de sus altezas, que tengan cargo delos vastymentos y del repartymiento dellos, para que a cada vno den lo que ha de aver, y ninguno non aya lugar de se quexar como hasta aqui se quexavan y dezian mal de las cosas que hazia juan doñate, y algunas dellas se pruevan". ${ }^{27}$ A pesar del poco airoso resultado de la gestión de Carvajal y sus hombres, los reyes seguían confiando en sus criados y continos como

\footnotetext{
y temor en Colón, quien todavía antes de zarpar debió temer un conflicto de autoridades — pues los continos iban al servicio de los reyes y difícilmente aceptarían la autoridad de Colón por encima de las instrucciones de Sus Altezas. A ello se deberá el interés de Colón en llevar continos propios. En la Real Provisión de 4 de agosto de 1493 dirigida a Juan Rodríguez de Fonseca, del Consejo, se le dice: "y cuanto a los continos que decís que toma el Almirante de las Indias, bien fue lo que le dijisteis que para este viaje no ha menester tomar continos algunos, pues todos los que allá van por nuestro mandado han de facer lo quél en nuestro nombre les mandare, y facer apartamientos suyos e ajenos podría traer mucho inconveniente...". Fernández de Navarrete: Colección de los..., pág. 354.

27 Berwick y Alba, duquesa de: Autógrafos de Cristóbal Colón y papeles de América. Madrid, 1892, págs. $1-3$.
} 
las personas más idóneas para cargos de responsabilidad. Al fin y al cabo el que éstos dependieran directamente de sus altezas, quienes les pagaban su salario, hacía a los continos gentes confiables y con presunción de recto cumplimiento del deber.

Para explicarnos mejor lo ocurrido en el gobierno de la Española, a partir de 1493, hay que recurrir a dos importantes documentos: el principal es una real provisión dada en Barcelona el 28 de mayo de 1493 por la cual los reyes daban poderes al almirante para otorgar cartas, provisiones y patentes en su nombre y selladas con el sello real. Y como "podría acaescer que vos non estuviésedes en las dichas islas... porque convernía que fuesedes a descubrir otras islas e tierra firme... a cuya causa habréis de dejar en vuestro lugar alguna persona que entienda e provea en las cosas de las dichas islas e tierra firme en vuestra absencia; el cual no podría entender ni proveer en ello dando las dichas nuestras cartas y provisiones en nuestro nombre, sin haber para ello nuestro poder e abtoridad: por ende por la presente damos poder e facultad a la persona que en vuestra absencia vos nombráredes para quedar en las dichas islas e tierra firme, para que pueda librar y expedir los negocios e causas que allí ocurrieren, dando las dichas cartas e provisiones en nuestro nombre, e sellándolas con nuestro sello, segund que vos lo podríades faser, seyendo presente en las dichas islas e tierra firme, por virtud de los dichos poderes que tenéis". ${ }^{28}$

Estos eran los poderes que recibieron los presidentes del Consejo Diego Colón y fray Bernal Buyl. Así se explica la libertad de acción del último, como que bajo su amparo y autoridad regresasen con él los descontentos de la factoría colombina en la más incuestionable legalidad. Buyl presumiblemente compartió con Diego Colón el proveer con el sello de placa real durante la ausencia del almirante.

El segundo documento para comprender el gobierno colombino es la instrucción de los reyes al almirante, virrey e gobernador de las Indias, dada en Barcelona el 29 de mayo de 1493. En ella se instruye "11. . Item: Que si fuere menester nombrar regidores, e jurados, e otros oficiales para administración de la gente, o de cualquier población que se hobiere de facer, que el dicho Almirante, Visorrey e Gobernador, nombre tres personas para cada oficio, como está sentado con Sus Altezas, e que dellas tomen Sus Altezas una para cada oficio, e así por provisión de Sus Altezas sean proveídos; pero porque por este camino no se puede proveer los dichos ofi-

28 Fernández de Navarrete: Colección de los..., págs. 338-339. 
ciales de esta manera, que por esta vez los nombre el dicho Almirante, e Visorrey e Gobernador en nombre de Sus Altezas". ${ }^{29}$

Así fracasó el intento del pimer "Visorrey de las Yndias" en crear un consejo a imitación del Consejo Real de Castilla. Un consejo nombrado por el almirante virrey, en nombre de sus altezas y haciendo uso del sello real. ${ }^{30}$ Que precisamente su invención se debió para subsanar el vacío de poder ocasionado por la ausencia de Cristóbal Colón, y el temor a un ataque portugués durante ella. Tal como el Consejo Real cuando faltaban los reyes, el consejo del virrey debía proveer y gobernar en su nombre mientras estuviera ausente aquél, incluso el número de sus componentes corresponde al de los seis gobernadores originales del Consejo Real. ${ }^{31}$ La presencia de Buyl como de los caballeros continos queda también justificada por la ley primera de las Cortes de Toledo de 1480 en que se estableció que debían residir permanentemente en el Consejo Real: un prelado, tres caballeros y ocho o nueve consejeros. ${ }^{32}$

Pero, siendo honrados, ¿se puede justificar la anomalía de la doble presidencia del consejo del virrey de las Indias desde la perspectiva del derecho castellano? No, pero sí en parte desde la del derecho aragonés. Si bien Colón en su carta al ama del príncipe, más tarde, escribió que "me juzgan como Governador que fue a Çecilia o ciudad o villa puesta en regimiento", rechazando el identicarse con los virreyes sicilianos, fueron tales virreyes aragoneses quienes sirvieron de arranque para su original idea de lo que era un "Visorrey e Gobernador". ${ }^{33}$

Cristóbal Colón creía ser el alter ego de Fernando e Isabel en las Indias, y no un simple gobernador. Desde esta perspectiva cobra interés el conocer que en la segunda mitad del siglo XV existieron en ocasiones dos virreyes gobernando a la vez en la isla de Sicilia, ocurriendo algo parecido

29 Ibídem, págs. 340-341.

30 Según De Dios "La designación de los consejeros estuvo reservada al rey, quien nunca delegó esta facultad. Por ello todos los títulos de consejeros que se conservan llevan la firma real...". Dios, Salustiano de: El Consejo Real de Castilla (1385-1522). Madrid, 1982, págs. 270-271. Podemos afirmar que el Consejo establecido en Indias, aún siendo nombrado en nombre de los reyes y con el sello real, constituyó un caso excepcional en el derecho castellano.

31 Tratándose del Consejo Real, su mismo ordenador, Juan I, testó en 1385 estando sobre Cellorigo de la Vera, que en caso de su muerte y hasta que su hijo alcanzase los quince años de edad el Reino se rigiese por "seis tutores e regidores e gobernadores"; quienes serían prelados, maestres de órdenes y caballeros junto con seis ciudadanos. Fue la guerra con Portugal y la derrota de Aljubarrota lo que causó el que el Rey de Castilla estableciera en las Cortes de Valladolid de 1385 la institución del Consejo. Ibídem, pág. 71.

32 Ibídem, pág. 255.

33 Colón: Textos y..., pág. 436. 
en Cerdeña. No debemos olvidar que para un genovés tal realidad no podía pasar desapercibida.

Por una provisión de 3 de agosto de 1477 Juan II nombró a Juan de Cardona virrey de Sicilia en sustitución de los virreyes Guillermo de Peralta y Guillermo Pujades, que desempeñaron tal dignidad mancomunadamente. El rey Fernando nombró en Tarazona, el 18 de febrero de 1484, a Guillermo de Peralta "Virrey y Gobernador General" de Cerdeña; sustituyendo interinamente a Jimeno Pérez Escrivá de Romaní — virrey — y a Juan Fabra — procurador regio de Cerdeña. Esta Procuradoría General era "una institución vinculada durante años al virreinato sardo y formaban un todo con éste". ${ }^{34}$ Este precedente debió llevar a Colón a nombrar dos lugartenientes, es decir, dos presidentes para su Consejo, siguiendo esa dúplice tradición de gobierno virreinal que había conocido en el Mediterráneo aragonés. Otra explicación resulta artificiosa.

A diferencia de los virreyes castellanos, la institución virreinal siciliana se encontraba claramente definida en el siglo XV, al tener continuidad — diferencia también que tenía de los virreyes de Cerdeña y de Mallorca. Eran los virreyes de Sicilia lugartenientes reales con amplísimos poderes y su fama se extendía por todo el Mediterráneo. Por ello el profesor Lalinde ha precisado: "podría concluirse que fue el virreinato siciliano el que inspiró las demandas colombinas, lo que no tendría nada de particular si se tiene en cuenta que, posiblemente su prestigio institucional ha sido superior al de los restantes virreinatos mediterráneos. Ahora bien, esto no debe conducir a suponer que Colón estudiara la figura del virrey siciliano para presentar sus demandas, debiéndose insistir que... debió obedecer al prestigio y al aspecto externo de las magistraturas". ${ }^{35}$ Es decir, Colón utilizó al virrey de Sicilia como modelo, sin un conocimiento profundo, pues no era letrado, desconociendo también las prerrogativas y competencias de la institución en Castilla.

Este desconocimiento es la causa de la originalidad del virreinato colombino. Y es que la Capitulación de Santa Fe debe ser interpretada tomando en cuenta las circunstancias únicas e irrepetibles de su acuerdo. Cuando el rey Fernando escribió a los oficiales de la Española, en carta de

34 Vicens Vives, Jaime: "Precedentes mediterráneos del virreinato colombino." Anuario de Estudios Americanos, T. V. Sevilla, 1948, págs. 585-588, 610-614. Era, Antonio: "Storia della Sardegna durante il regno di Fernando il Catolico". V Congreso de Historia de la Corona de Aragón. Zaragoza. 1952, pág. 12.

35 Lalinde Abadía, Jesús: "El régimen virreino-senatorial en Indias". Anuario de Historia del Derecho Español. Madrid, 1967, Tomo XXXVII, págs. 36-41. Rumeu: Nueva luz..., págs. 226-229. 
23 de febrero de 1512, comentando las condiciones que Juan Ponce había demandado para la Capitulación del Biminí, hacía memoria de lo ocurrido en 1492: "la capitulacion que el nos enbio sobre ello va con esto y cierto es muy desonesta y apartada de razon porque todo lo que agora se puede descubrir es muy facil de descobrir y no mirando estando todos los que hablan en descobrir quieren tener fin a la capitulaçion que se hizo con el almyrante Colon y no piensan como entonces nynguna esperança avia de lo que se descubrio ny se pensaba que aquello pudiese ser la merced que yo le hago" ${ }^{36}$ Aquel privilegio extraordinario, la Capitulación de Sante Fe, lo concedió el rey católico por no contrariar a la reina, teniendo la seguridad interior que nunca hallaría Colón tierra y que por tanto aquella arbitrariedad jurídica sería inejecutable. No existe otro enigma.

Como hemos dicho, existía el miedo a un ataque de los portugueses a la fortaleza y villa de los castellanos en las Indias, cualquier duda desaparece con esta cita de las Décadas del Nuevo Mundo: "Explorada así las estas cosas con diligencia en la entrada de la provincia de Cibao, el día primero de Abril, víspera de la Resurrección, se volvió a la Isabela, pues éste era el nombre de la ciudad, dejando en el gobierno de ella y de toda la isla a su hermano y a cierto Pedro Margarit... y se dispuso a recorrer la tierra que él juzgaba continente, y distaba sólo de allí setenta millas, acordándose del precepto del Rey que le había encargado que se apresurase a recorrer cuantas cosas nuevas pudiera, no fuera que algún otro rey quisiera sujetar antes a su poder aquellas regiones. Pues el rey de Portugal decía públicamente que le tocaba a él descubrir lo que había oculto por allá... ".37

Por ello la ida de Margarit y de los escuderos de la Española, sin recibir posteriormente castigo alguno, señala la autorización de fray Bernal y posiblemente de la mayoría del Consejo; quizás en las naves que trajeron a Bartolomé Colón a finales de junio de 1494 hubo cartas reales para los miembros del Consejo con instrucciones y noticias precisas que nos son desconocidas, éstas últimas debieron dar aviso de lo avanzado de la negociación con Portugal lo que el ducho diplomático Buyl interpretó como

36 Murga Sanz, Vicente: Juan Ponce de León, fundador y primer gobernador del pueblo puertorriqueño. San Juan, 1959. Apéndice XV, págs. 289-299. Manuel Ballesteros reparó en la importancia de ese pasaje. Ballesteros Gaibrois, Manuel: Juan Ponce de León. Protagonistas de América. Madrid. 1987. Sobre la génesis del virreinato colombino, véase mi trabajo: "Virreyes de Aragón y Virreyes de Indias. El desarrollo institucional obra del Rey y del Almirante", presentado en Zaragoza en julio de 1996 en el VII Congreso Internacional de Historia de América de la AEA, cuyas actas se encuentran en vías de publicación.

37 Anglería: Décadas del... 
indicación de lo poco probable de un conflicto inmediato con el vecino reino. Por ello el embarque de Margarit y de los escuderos de la isla se hizo de forma ordenada y pacífica. ¿Si ello hubiera sido contra la voluntad de Fernando e Isabel, cómo Margarit mantuvo su oficio de contino del rey? Y a los escuderos sólo "por sus hermanos del dicho Almirante les fueron tomados los cavallos que avian llevado, para que quedasen alla, porque los avian menester para proveymiento de algunas cosas complideras a nuestro servicio". ${ }^{38}$ Acción que se justificó sea por la necesidad de caballos para la conquista, sea porque los Colón seguían temiendo a los portugueses, o por ambas razones.

Buena prueba de cuál era la intensidad de la conflictividad prebélica vivida todavía entonces, y contraria a las paces de las Alcáçovas en el mar, la da el siguiente fragmento de la carta que el 17 de julio de 1494 enviaron los reyes al corregidor de Guipúzcoa para que no se molestasen más a las naos portuguesas, a sus cargas y a sus naturales: "Nos es dicho que algunos nuestros subditos e naturales que andan por la Mar han tentado algunas veces de hacer mal y dapño a los subditos del Serenisimo Rey de Portugal nuestro Hermano que andan por la mar, aviendo que entre Nos y el e nuestros subditos e naturales e los suios que non havia ni hay paces asentadas y juradas e porque alliende de las paces que antes de agora entre Nos e el estaban y estan asentadas por el deudo que con Nos tiene y amor que le tenemos sus subditos y naturales queremos que sean tratados por los nuestro como los nuestros propios... ". 39

\section{El baçín de Caonaboa y la experiencia portuguesa}

La carta fechada a finales de abril de 1494, y que narra la exploración del Cibao, dice en el folio 10 recto al ponderar la riqueza aurífera de los ríos del cacicazgo de Caonaboa: "Este es aquel que dizen que mató a nuestros christianos, y en todos cavos del Çibao los conoçian y andavan desmandados unos de otros; y este Cahonaboa dizen que en la tierra donde vive ay mui mucho oro, mas es tierra mui montañosa, y que los pedazos y granos son mui grandes. Yo lo creo por lo que me dixo Ocanaguari de Pedro, rrepostero, y de Escobedo quando me dixeron que le rrogó que lle-

38 Ramos: El conflicto de..., págs. 125, 136.

39 Biblioteca de la Real Academia de la Historia, Colección Vargas Ponce, Vol. XLVII, fols. $320 \mathrm{v}-321 \mathrm{v}$. 
vase consygo a mostrar la mina de oro y quél lo hizo ansí; y que después le rrespondió que aquel oro hera poco y los granos pequeños, y que no quiso salvo yrse a este caçique Cahonaboa; llevaba un baçín, y le mató". ${ }^{40}$

Hay diversos aspectos de esta cita que merecen atención. En primer lugar, la salida de Escobedo y del repostero no fue impulsiva sino fruto de una decisión premeditada siguiendo las instrucciones que les habían dejado, el que debían encontrar la "mina" de oro. El comportamiento del contino y del repostero tenía precedentes en la historia de los descubrimientos, me refiero a la exploración del río Congo aguas arriba efectuado por Diogo Câo. Y bien es posible que los tenientes de Colón la tuvieran en cuenta, pues participó en el primer viaje — si no quedó en la Navidad- Rodrigo de Xerez, vecino de Ayamonte, quien había vivido en Guinea, y que en compañía de Luis de Torres había oficiado de embajador de Colón internándose en Cuba buscando al Gran Khan. ${ }^{41}$

Câo, entre 1482 y 1483 , descubrió para el rey $1.500 \mathrm{kms}$. de costa africana, colocando padrôes por toda ella e iniciando la práctica portuguesa demarcatoria por medio de pétreo amojonamiento. El 8 de abril de 1484 don Joâo le ennobleció y le dio un escudo con dos padrones sobre dos montes en campo de plata que significaba el mar, precedente heráldico del escudo otorgado a Colón por los reyes de Castilla. En su segundo viaje africano Câo exploró también tierra adentro, y se alejó de la costa siguiendo el cauce del río Congo, río arriba. A 160 kms. de su desembocadura en los roquedos de Yelala grabó la célebre inscripción que perdura hasta nuestros días dando fe de hasta donde llegó la expedición en nombre del rey de Portugal. Buscaba al preste Juan y el conocer el secreto de la tierra, sus recursos. En su segundo viaje de descubrimiento, Câo tenía poderes de embajador, pues en el primer viaje inició las relaciones entre el rey del Congo y Portugal, que tanto valoraría Juan II. ${ }^{42}$ Siguió la embajada de Rui

40 Libro Copiador, pág. 475. En la misma carta Colón escribía: “todos nos maravillamos como estos yndios ayan osado matar los dichos christianos que quedaron acá, el qual propósito dixe por los de Cahonaboa, el qual dize que tiene mucho oro en la tierra donde vive y son pedazos grandes, que no los coje en los rríos salvo en la tierra dentro escarvando, y por esto quiso yr allá Pedro rrepostero, y Escobedo. Yo lo traxe a propósito por el oro menudo que les amostrava Ocanaguari, y que rrespondió que no lo quería menudo, salvo grandes pedazos, y que se quería yr a este Caonaboa, como se fue...". Ibídem, págs. 480-481.

41 Gould: Nueva lista..., págs. 165, 442-447. Es de suponer que tanto el intérprete Torres como Xerez, acompañaron tierra adentro a los dos Tenientes asesinados por orden de Caonaboa. Sobre mis dudas respecto de la muerte de Xerez en la Española, ver el trabajo de Adam Szászdi Nagy y de István Szászdi: "La llegada de Colón a Boriquén y la crisis luso-castellana de 1493". Homenaje al historiador y líder cívico Aurelio Tió. San Juan de Puerto Rico, 1993, págs. 287-316.

42 Hermano Saravia: Historia de Portugal. Madrid, 1989, págs. 158-160. 
de Sousa de carácter comercial y misional que consiguió la amistad y conversión del rey negro y de su corte. El rey y su familia se bautizaron tomando los nombres de la familia real portuguesa. Así el rey se llamó Joâo, su hijo mayor Afonso - como el príncipe heredero portugués- , y su tío Manisoño escogió el nombre de Manuel en honor del duque de Beja - hermano de la reina doña Leonor - . La política de aproximación y "conversación" con los indios del primer viaje colombino, y en parte del segundo, parecen seguir las pautas del modelo portugués en el Africa negra.

Joâo Afonso de Aveiro, comandante de una de las naos de la armada de Azambuja, regresó al reino de Benín — que era cercano a San Jorge de la Mina - con misioneros enviados por el príncipe Perfecto para predicar a su rey. Para fines del siglo XV se había creado un triángulo comercial de la trata esclavista y del oro en polvo: Mina-Benín y la isla de Santo Tomé. Se fundó una factoría en Guató, puerto del reino de Benín, y se procedió a explorar el curso del río Níger hasta 100 leguas de la costa, llegando hasta el reino de Opu. Joâo Afonso de Aveiro murió de enfermedad intentando afirmar la presencia portuguesa en la zona. En 1494, Jerónimo Münzer conoció en Portugal negros que se preparaban para recibir las órdenes sacerdotales y ser devueltos a su continente. Otro caso en que religión, política y comercio se mezclaron fue el de un rey amigo del río Senegal, el rey Bemoim, quien destronado pidió ayuda a los portugueses. Bemoim viajó a Portugal donde fue acogido por el mismo Joâo II, quien le apadrinó en su bautismo. El rey africano prometió la conversión de su pueblo y una alianza firme con los lusitanos. En 1490 partió por el Tajo de regreso, en una armada con misioneros dominicos entre los cuales viajó el propio provincial fray Alvaro quien quiso dirigirlos en persona. Bemoim murió apuñalado por el comandante Pero Vaz da Cunha dando al traste con la embajada. ${ }^{43}$

La necesidad de asegurar el control de la mina de Caonaboa, al igual que del comercio con el cacicazgo amigo de Guacanagarí, llevó a la fundación del Fuerte de la Navidad, sede de una factoría comercial y una fortaleza contra los indios enemigos del interior y exterior de la isla como una construcción destinada a intimidar a otros cristianos tentados por la codicia

43 Rodrigues, Vitor: "Benim". Dicionário de história dos descobrimentos portugueses. Direcçao de Luís de Albuquerque. Coordenaçâo de Francisco Contente Domingues. 1994. vol. I, páginas 129-131. Rosario OP., Frey Antonio do: "Missionaçâo". Ibídem, vol. II, págs. 746-747. Simoes Lopes, Marilia: "Congo". Ibídem, vol. I, págs. 285-286. Para el Rey del Congo, consúltese a Rui de Pina: Cronica de El-Rei Dom Joâo II. Edición anotada por Alberto Martins de Carvalho. Coimbra, 1950, págs. 152-174. 
que pudieran creer tener mejor derecho sobre la isla Española (es decir los portugueses). Pero ni Colón ni Fernando e Isabel innovaron nada al tomar esa medida militar. Al poco de subir al trono, Joâo II, siguiendo su política de asegurar para su reino el espacio geográfico reconocido por los castellanos en el tratado de las Alcaçovas, hizo levantar la fortaleza de San Jorge de la Mina. Aquel castillo se levantó con piedra llevada desde Portugal con la intención de crear un enclave permanente protegido de los naturales y el hacer cumplir a los marinos andaluces lo establecido en Alcaçovas-Toledo. Era la manera de hacer respetar en tierra el señorío portugués de la navegación de Guinea. ${ }^{44}$

Existe un pasaje de la carta colombina de fines de abril de 1494 que narra la exploración del Cibao, y a la que hemos hecho referencia anteriormente, que describe la suerte de Escobedo a manos de Caonaboa: "y que no quiso salvo yrse a este caçique, Caonaboa llevava un baçín y le mató". ¿Pero qué significa ese baçín? La solución esclarecerá parte del enigma de la muerte de Escobedo y de Gutiérrez, quienes se habían llevado a sus mujeres, y a un niño que había tenido el repostero. La voz baçín tiene diversas acepciones. En el Memorial Portugués de 1494 figura en un interesante pasaje, que por su extraordinario interés reproduzco a pesar de su extensión: "Lo de aquesta verdadera Mina de Guinea ssepa Vuestra Alteza que aqueste oro delha es todo lo de que sse proveia Espanha toda hy aun Italia, hy aqueste venia da questa propia tierra de Guinea e Mina por tierra con mucho trabajo i peligros a Tunez hy prinçipallmente a Mon de Barcas que es hun lugar çerca de la mar en aquelha costa y no muy lexos de Tunez i traian ell dicho oro assy como ell agora viene de la Mina, hy lo traian en camelhos, y los dichos negros que lo traian delhos a ssus espaldas, e lhevavan en rretorno delho de aquestos alanbes i panhos moriscos y alcatifas pequenhas de las de Veneçia i otras cosas que les conplian para ssu tierra, i de aqueste oro da questa propia tierra de Guinea hy Mina lhevavan las galeaças de Veneçia i de Florençia de Tunez i de Mon de Barcas por ssus mercaderias i los espanholes en ell tienpo que tenian paz hy amistad con el Rey de Tunez i con todos las tierras de moros de Africa, i tratavan elhos alha i los moros venian i tratavan aqua como en ssu propia tierra i mas francamente aun i mejor, hy aqueste oro venia assy mismo a Fez i de Fez aqua a Espanha, assy por via de trato i mercaderias, hy con ell hy en aquesta manera sse enrriqueçio tanto Espanha como en aquelhos tienpo era, hy

44 Cortesao, Jaime: "Os Descobrimentos Portugueses." Obras Completas, vol. III. Lisboa, pág. 570. Sottomayor, Pedro: "Mina”. Dicionário de..., vol. II, pág. 738. 
aqueste oro era ell que venia al Reyno de Granada de limosnas i por ssu sseda i mercadorias dell dicho Reino ell quall era aqueste mismo oro de la Mina de Guinea hy assy en polvo i sse lhamava tibar, hy de aqueste venia a Castilha en ssus mercadorias i tratos, hy era elha proveida de oro porque de otras partes ni modos ny maneras no lo podia ny puede ser, i de aqueste oro quando venia ha aquelhas partes de Tunez etc. hy sse traya hy enbiava a Granada assy de limosna como para lhevar ssus mercadorias sse tomavan muchas vezes hy muchas por castelhanos i portogueses, e assy por otros, en navios moriscos en que lo passavan quatro mill hy çinquo mill hy diez mill pesos aquelhos moros dizen miticales de oro en polvo este propio de la Mina de Guinea a que elhos lhaman tibar, hy yo por my estando en Çepta, vy traer ay tomados navios de moros que passavan a Granada con quatro hy çinco mill miticales de oro hy sse de perssonas de gran manera de Portogall hechos i rricos i de muy gran fazienda ssolo de presas que tomaron con aqueste oro passandolo a Granada, hy el Senhor Don Halvaro presydente dell Conssejo de Vuestra Alteza que naçio en Çepta le dira i dara informaçion de lo que çerca desto ay vido, hy quando la cantidat de aqueste oro para passar de Tunez a Granada era muy grande por las limosnas sseren muchas que se dezia ell baçin de Granada hy ell otro oro de mercaderes passavan lo en carracas hy naos muy gruessas, hy tanto que aquesta via de Guinea hy quanto mas sse lhego a la Mina sse començo a descobrir i tratar tanto luego por los grandes trabajos i peligros que rreçebian los negros i guineos en hir a Tunez hy a Mon de Barcas çessaran de lhevar ell dicho oro alha, i ny alha ny aqua no va ny viene, con esta burla hy enganho daqueste Rey de Portogall hy çegedat i mengua de verdadero conoçimiento hy informaçion de la verdat de aqueste caso de toda la cristiandat hy en espeçiall de los mas vezinos hy comarcanos i ssobre todos de aquesta vuestra Espanha i de Vuestras Altezas ssenhores hy governadores delha la quall nunqua otro ssostenymiento ny bien tenporall tuvo ni pudo ny puede tener para aver oro i moneda de plata ssy aqueste i por la atras dicha manera no, hy acabado que aquesta çesso esta como esta i cada vez ssera mas pobre fasta no sse falhar en elha, pieça de oro ni de plata, aquesta generall çeguedat en aqueste caso pongo yo que es por ell danho de aquesta cosa sser aun rrezente que no es prinçipallmente que de quarenta anhos aqua, hy por las turbaçiones hy fatigas que en aquestos tienpos sse sseguieron a la cristiandat, assy como a Italia hy a todo levante en lo dell turco hy a Espanha las que Vuestra Alteza ssabe...." Insistiendo a continuación que la política de sigilo portuguesa permitía el que el reino de 
Portugal guardara para sí el corso y rescate del oro africano: "hy junto con aquesto la mengua de verdadera informaçion i conoçimiento de la verdat de aquesto que no digo Françia hy Ingratierra que ienerallmente lo tienen hy creen mas aun en Vuestra Espanha muy muchos, que Guinea es una Isla hy pequenha i toda del Rey de Portogall hy que en elha es aquesta Mina de Oro ssuya hy que ell tiene hun castilho ssobrelha hy que elha esta dentro en ell castilho. I que de alhy manda ell traer ell oro" ${ }^{45}$ En este contexto el baçín se relaciona con la limosna dirigida para mantener al Islam y la guerra santa contra los infieles conocida como el azaque, y que en realidad era un tributo forzoso. ${ }^{46} \mathrm{La}$ renta del azaque fue vital para la resistencia del reino granadino contra los cristianos. ${ }^{47}$

La palabra bacín tiene un origen latino antiguo y pervivió tanto entre los cristianos como en el vocabulario mozárabe de la lengua ordinaria de la población hispanomusulmana. ${ }^{48}$ Así se halla en ambas orillas del Mediterráneo y significa, como su sinónimo bacía, distintos tipos de vasijas o fuentes de ancha boca. Esas fuentes casi planas, platos y escudillas también servían para recoger limosna, por lo cual desde el siglo XVI se relaciona la voz baçín con las limosnas mismas. ${ }^{49}$ Estas bacías de mayólica con esmaltes metálicos en ocasiones, fabricadas en Al Andalus entre otros sitios del mundo mediterráneo, eran muy apreciadas en el norte de Italia entre los siglos XI y XV, donde eran conocidas como bacini.$^{50}$ Este artículo de comercio alcanzó extraordinaria difusión, no sólo en las tierras bañadas por el Atlántico norte, sino en las cálidas aguas del mar de Guinea.

En 1479, el mercader flamenco Eustache Delafosse, a bordo de naos castellanas andaluzas, navegó a las aguas prohibidas de la costa guineana donde fue hecho prisionero por el mismo Diogo Câo. Su relación de viaje

45 Folios 9-14. Véase nuestra transcripción y estudio en István Szászdi y Katalin KlimesSmik: El Memorial Portugués.

46 Torres Delgado, Cristóbal: "El reino nazarí de Granada (1232-1492). Aspectos socio-económicos y fiscales." Actas del II Coloquio de Historia Medieval Andaluza. Sevilla, 1982, págs. 326-327.

47 Para el azaque consúltese mi trabajo de próxima publicación: "El derecho del azaque y Granada", en La España Medieval, Madrid.

48 Sobre este último particular me remito a los conocidos estudios al respecto de don Ramón Menéndez Pidal.

49 Ver las eruditas anotaciones de la Dra. Klimes-Smik relativas a baçin en el glosario del Memorial indicado en la nota 1, pág. 148. Bacin, además de limosna, por analogía a ésta, llegó a ser metal de poco valor. En una valuación de las mercaderías extranjeras y su precio en la villa de Bilbao de 26 de abril 1563, figuran: "Canillas de oro de bacin que es falso la libra de doce onzas cinco reales.... 170". Guiard y Larrauri, Teófilo: Historia de la noble villa de Bilbao. Bilbao, 1971, t. I, pág. 513.

50 Constable, Olivia Remie: Trade and traders in Muslim Spain. The commercial realignment of the Iberian Peninsula (900-1500). Cambridge, 1994, págs. 24-27, 190-191. 
constituye un vivo relato que nos hace pensar en las primeras relaciones de Indias. En ella ofrece los bienes objeto de comercio con los guineos: "Et nous coustoient la mere et l'enfant ung bachyn de barbier et 3 ou 4 grandz anneaulx de letton d'achapt". ${ }^{51}$ Así se puede comprender que Colón tuviera bacines para rescatar oro. El sábado 29 de diciembre de 1492 se lee en el diario: "Siendo ya de noche le envio al rey [Guacanagarí] una gran carátula de oro, y envióle a pedir un bacín de aguamanos y un jarro. Creyó el Almirante que lo pedía para mandar hacer otro, y así se lo envió". ${ }^{2}$ Ciertamente los bacines, y más si eran de latón, debían ser un regalo principesco para los caciques taínos, pues Colón, en la carta que escribió a los reyes en octubre de 1495, al notificarles de los acuerdos que había celebrado con los caciques para la tributación de oro, dice: "Les dixe que yo me dexaría de cavar las minas si me querían dar, en nombre de Vuestras Altezas, cada quatro lunas, lleno, la mitad de un caxcavel dello, de oro, cada cabeza, y ellos dixeron que los plazía... cogen lleno un caxcavel en que avía más de ocho castellanos... Concluí con ellos que me darían el dicho caxcavel a las cuatro lunas, e yo daría al caçique prinçipal un baçin y a los dos tureyes en foja, ques latón tanto como el dedo"..$^{53}$ Ante esta evidencia cabe pensar que la embajada de Escobedo y de Gutiérrez buscaba no sólo el explorar el interior y hallar la mina, sino encontrar a Caonaboa y entablar amistad; si es posible consiguiendo su voluntaria tributación de oro.

Quisieron emular las proezas guineanas que conocían haber hecho hombres como Diogo Câo y recibir al almirante con un rico tesoro. Tal como él les había dejado instruído. Para ello: "Dejóles todas las mercaderías, que los Reyes mandaron comprar para los resgates, que eran muchas, para que las trocasen y resgatasen por oro, con todo lo que traía la nao. Dejóles también pan bizcocho para un año y vino y mucha artillería, y la barca de la nao para que ellos, como marineros que eran los más, fuesen, cuando viesen que convenía, a descubrir la mina de oro, porque a la vuelta el Almirante hallase mucho oro.... ${ }^{54} \mathrm{La}$ Española no era la Mina, ni Caonaboa era el rey del Congo, sólo el baçín resultó ser el yelmo de Mambrino.

51 Delafosse, Eustache: Voyage d'... sur la côte de Guinée, au Portugal et en Espagne (1479-1481). Edición de Denis Escudier. París, 1992, págs. 24-25.

52 Colón: Los cuatro viajes..., pág. 114. Como curiosidad recojo que en el inventario que en 1487 se hizo al secuestrar los bienes del capitán corsario Iñigo de Artieta, en Lequeitio, se apunta: "Yten, vn agoamaril con su baçin." Colección documental del Archivo Municipal de Lequeitio. T. II. Fuentes documentales medievales del País Vasco. San Sebastián, 1992, pág. 428.

53 Libro Copiador, pág. 529.

54 Colón: Los cuatro viajes... 
El trato benigno con Caonaboa por parte del almirante obedeció a que quiso enviarlo vivo a sus altezas, con la idea que siguiendo el ejemplo de los reyes africanos enviados a Portugal, sirviese a su regreso a la Española como instrumento de la asimilación y penetración castellana. El 15 de octubre de 1495 el almirante del mar océano escribía a sus altezas desde la Maguana: "Yo enbío a Vuestras Altezas a Caonaboa y su hermano; éste es el maior caçique de la ysla y más esforçado y de yngenio; si éste deprende a hablar, dirá todas las cosas desta tierra mejor que nadie, porque no ay cosa que de toda suerte quél no sepa."

En la misma carta Colón escribe: "enbié una fusta de rremos a descubrir la ysla de Babueca... y fallaron grandes pesquerías y en espeçial caçones, según dixeron, e en cantidad, como al cavo de Bojador, en Guinea, allí donde tenían el debate los de Palos con los portugueses... tornó aquí la fusta sin que pudiese tornar a mirar esto, esta pesquería, la qual, si ansí es como cuentan, vale tanto como una mina, porque en Guinea no pueden pescar, salvo dos meses del año, y aquí pescarán de contino". ${ }^{55}$ ¿Parámetro o espejismo? Colón quiso recrear Guinea en el Nuevo Mundo.

55 Libro Copiador, págs. 537-538, 541. 